\title{
Modeling and Simulation of an Improved Impact Force Model for Mechanical System
}

\author{
Xupeng Wang*, Xiaomin Ji, Lu Wang, Dingjun Wang and Bimeng Han \\ Department of Industrial Design, Xi'an University of Technology, Xi'an, 710054, China \\ ${ }^{*}$ Corresponding author
}

\begin{abstract}
Impact is universal phenomenon in mechanical system with clearance. In order to accurately describe the effect of impact between journal and bearing in clearance joint, an improved contact force model is presented in this work, which assumes the coefficient of restitution during impact is varied, and sets up the modeling of restitution coefficient related to initial impact velocity and yield strength of material. Then the improved contact force model is validated based on a great number of numerical simulations and a typical pendulum experimental test rig, the numerical results are in reasonable agreement with those experimental results, furthermore, the relative errors are all no more than $10 \%$ between numerical and experimental results. It can be concluded that the improved contact force model is effective, and can exactly describe the impact effects between two bodies in mechanical system.
\end{abstract}

Keywords-modeling and simulation; impact; improved contact force model; coefficient of restitution; mechanical system

\section{INTRODUCTION}

It is well known that the clearance is inevitable between adjacent two parts in mechanical system due to errors caused by design, manufacture, and assembly, as well as demand of relative motion [1], which lead to the contact and impact are universal phenomenon in multibody systems. And also makes the value of impact force between two parts with relative motion, such as journal and bearing, is enlarged obviously, which further lead to vibration, shock and nonlinear of system's dynamic appearance, even cause failure of the whole mechanical system [2-5]. Therefore, it can be concluded that the accurate modeling of impact is critical for dynamic simulations of mechanical systems.

Over the several past decades, a great number of researchers all over the world focus on the modeling and analysis of impact and its effect on the dynamic of multibody systems, several different contact force models have been presented to represent impact effects between two bodies, especially in clearance joint such as journal and bearing [6-15]. The classical pure elastic contact force model was present by Hertz [6]. Liu et al. extended the Hertz's model [7], and introduced another pure elastic contact force model, which has a wider application range than the Hertz's model. In order to overcome the drawback of pure elastic contact force model, several dissipative contact force models have been published. Hunt and Crossley presented a dissipative contact force model with a nonlinear viscoelastic term related to restitution coefficient and initial impact velocity [8]. Lankarani and Nikravesh further improved the model of Hunt and Crossley, and introduced another contact force model, which is most popular and frequently used [9]. Gonthier et al. [10], Zhiying and Qishao [11], Flores et al. [12], Bai and Zhao [13], Wang and Liu [14] also proposed different dissipative contact force models, which have a wide range of restitution coefficient.

But for all these impassive contact force models above, the restitution coefficient is assumed to be a constant value. In fact, the coefficient of restitution is related to the parameters of material, structure, initial impact velocity, even the yield strength of material. So the published impassive contact force models above are approximate. Thus, this research is mainly devoted to study the influence factors of restitution coefficient during impact process, and then modeling and analysis for the frictionless impact between adjacent two parts with relative motion in mechanical system.

\section{AN IMPROVED CONTACT FORCE MODEL}

As illustrated above, the coefficient of restitution is defined as constant parameter in contact force models [6-14]. In fact, restitution coefficient is related to the parameters of material, structure, initial impact velocity, even the materials' yield strength.

Stammers et al. presented a restitution coefficient based on initial velocity of impact [15], which can be calculated as

$$
e=1-0.26 v^{1 / 3}
$$

where $V$ is the initial impact velocity.

From the experimental results, Zhang and Sharf find that the Yield strength of material also has obvious influence on the impact effects, and need to be considered in the calculate of impact [16].

In order to consider the influence of initial impact velocity and the materials' Yield strength on the restitution coefficient, as well as the impact force, the paper extends the works of Wang and Liu [14], Stammers et al. [15], and Zhang and Sharf [16], then introduces an improved impact force model, which is evaluated as

$$
\begin{aligned}
& F_{N}=K_{i} \delta^{n}+D \dot{\delta} \\
& =K_{i} \delta^{n}\left(1+\frac{3\left(1-c_{r}{ }^{2}\right) e^{2\left(1-c_{r}\right)}}{4 \dot{\delta}^{(-)}} \dot{\delta}\right)
\end{aligned}
$$


where, $K_{i}$ is the contact stiffness, $\delta$ is the relative indentation, $\dot{\delta}^{(-)}$is initial impact velocity, $\dot{\delta}$ is the relative velocity between two parts of impact, and $c_{r}$ is the modified coefficient of restitution, which can be written as

$$
c_{r}=1-0.26 K^{*} \dot{\delta}^{(-)^{1 / 3}}
$$

where $K^{*}$ is the coefficient relate to the Yield strength of materials, and is expressed as

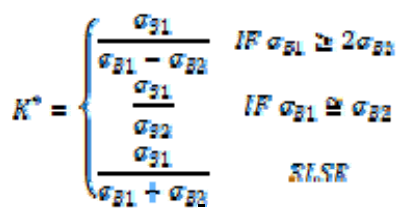

where $\sigma_{B 1}$ and $\sigma_{B 2}$ are the yield strength of materials.

\section{APPLICATION: NUMERICAL AND EXPERIMENTAL}

Fig. 1 shows another typical impact pendulum test rig [16], which contains a steel ball, a cylindrical specimen and an accelerometer, as well as a digital video camera with a frame rate of 1000 frames/s.

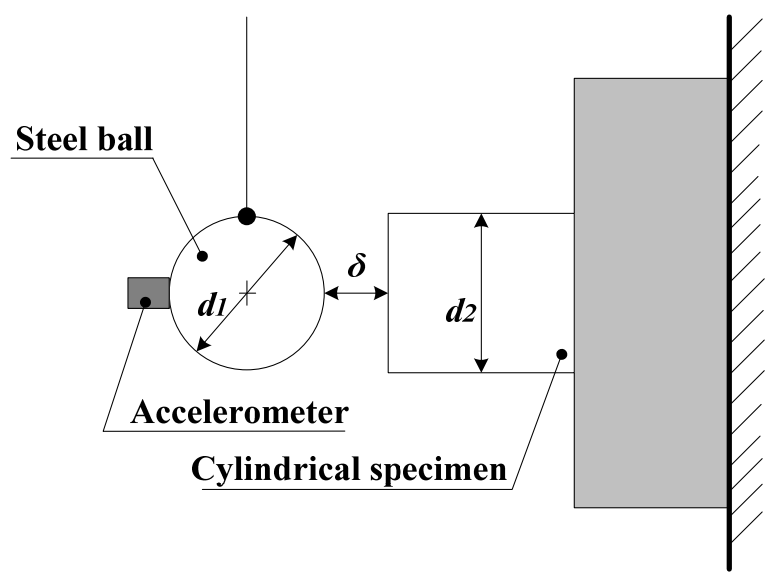

FIGURE I. EXPERIMENTAL RIG: IMPACT BETWEEN A STEEL BALL AND A CYLINDRICAL SPECIMEN (MODIFIED FROM [16])

The steel ball is released from a pendulum angle, and the cylindrical specimen is fixed with platform as depicted in Fig.1. The initial and depart velocity are measured by the digital video camera, and then the coefficient restitution is also formulated. Meanwhile, by measuring the acceleration of the steel ball during impact process, the impact force between the surface of steel ball and cylindrical specimen is also can be formulated from the Newton's second law as $F=m a$, where $\mathrm{m}$ and a are the mass and acceleration of steel ball, respectively.

In order to study the effects of Yield strength of material on the restitution coefficient and impact force, two different materials of cylindrical specimen (C1 and C2) are selected as shown in Table 1.
TABLE I. MATERIAL PROPERTIES OF IMPACTING BODIES

\begin{tabular}{|c|c|c|c|c|}
\hline $\begin{array}{c}\text { Impacting } \\
\text { bodies }\end{array}$ & $\begin{array}{c}\text { Young's } \\
\text { modulus } \\
\text { (GPa) }\end{array}$ & $\begin{array}{c}\text { Poisson's } \\
\text { ratio }\end{array}$ & $\begin{array}{c}\text { Yield } \\
\text { strength } \\
\text { (MPa) }\end{array}$ & $\begin{array}{c}\text { Yield } \\
\text { contact } \\
\text { force (N) }\end{array}$ \\
\hline C1 & 213 & 0.29 & 1815 & 6674 \\
\hline C2 & 205 & 0.29 & 330 & 42 \\
\hline Ball & 210 & 0.3 & 2050 & - \\
\hline
\end{tabular}

TABLE II. RESULTS OF VELOCITY AFTER IMPACTING FOR SPECIMEN C1 AND C2

\begin{tabular}{|c|c|c|}
\hline \multirow{2}{*}{$\begin{array}{l}\text { Initial impact } \\
\text { velocity [m/s] }\end{array}$} & \multicolumn{2}{|c|}{ Velocity after impact [m/s] } \\
\cline { 2 - 3 } & Specimen $\mathbf{C} \mathbf{1}$ & Specimen C2 \\
\hline 0.0938 & 0.0885 & 0.0799 \\
\hline 0.1500 & 0.1400 & 0.1239 \\
\hline 0.2060 & 0.1907 & 0.1660 \\
\hline 0.2989 & 0.2737 & 0.2330 \\
\hline 0.3910 & 0.3548 & 0.2965 \\
\hline 0.5000 & 0.4496 & 0.3687 \\
\hline
\end{tabular}

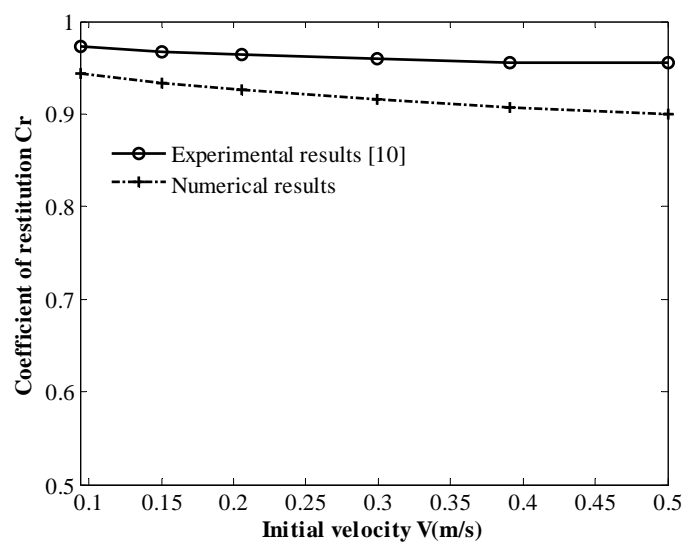

(a)

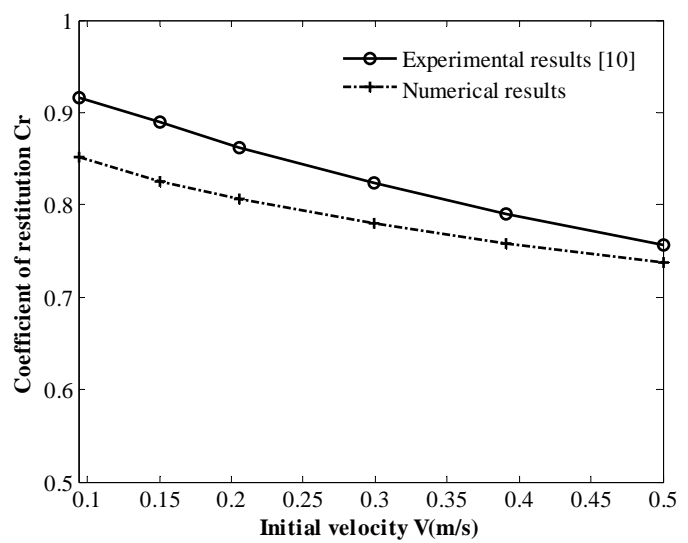

(b)

FIGURE II. COEFFICIENT OF RESTITUTION: (A) SPECIMEN C1; (B) SPECIMEN C2

As described in Table 2 and Fig. 2, (1) with the increase of initial impact velocity, the depart velocity of specimen $\mathrm{C} 1$ and specimen C2 are all decreased, which is coincident with the results of application1. (2) Although the initial impact velocity is identical, the value of velocity after impact based on $\mathrm{C} 1$ is larger than C2 all the time, which is due to the material's yield strength of $\mathrm{C} 1$ higher than $\mathrm{C} 2$. 
Table 3 and 4 illustrate the experimental and numerical results for $\mathrm{C} 1$ and $\mathrm{C} 2$, it can be identified that with the increase of initial impact velocity, the relative errors of $\mathrm{C} 1$ and $\mathrm{C} 2$ are also changed, but the values are less than $10 \%$, which further validated the improved model presented above. Meanwhile, it also can be concluded that the yield strength of material has obvious influence on the restitution coefficient of impact, the higher value of Yield strength, the larger coefficient of restitution.

TABLE III. RESULTS OF RESTITUTION AND CORRESPONDING PERCENTAGE ERROR BASED ON EXPERIMENTAL AND NUMERICAL FOR SPECIMEN C1

\begin{tabular}{|c|c|c|c|}
\hline \multirow{2}{*}{$\begin{array}{c}\text { Initial impact } \\
\text { velocity [m/s] }\end{array}$} & \multicolumn{3}{|c|}{ Restitution coefficient of Specimen C1 } \\
\cline { 2 - 4 } & Experimental & Numerical & Error [\%] \\
\hline 0.0938 & 0.9735 & 0.9435 & 3.08 \\
\hline 0.1500 & 0.9672 & 0.9333 & 3.50 \\
\hline 0.2060 & 0.9647 & 0.9257 & 4.04 \\
\hline 0.2989 & 0.9596 & 0.9157 & 4.58 \\
\hline 0.3910 & 0.9555 & 0.9074 & 5.03 \\
\hline 0.5000 & 0.9547 & 0.8992 & 5.81 \\
\hline
\end{tabular}

TABLE IV. RESULTS OF RESTITUTION AND CORRESPONDING PERCENTAGE ERROR BASED ON EXPERIMENTAL AND NUMERICAL FOR SPECIMEN C2

\begin{tabular}{|l|l|l|l|}
\hline \multirow{2}{*}{$\begin{array}{l}\text { Initial impact } \\
\text { velocity [m/s] }\end{array}$} & \multicolumn{3}{|c|}{ Restitution coefficient of Specimen C2 } \\
\cline { 2 - 4 } & Experimental & Numerical & Error [\%] \\
\hline 0.0938 & 0.9166 & 0.8518 & 7.07 \\
\hline 0.1500 & 0.8892 & 0.8260 & 7.11 \\
\hline 0.2060 & 0.8612 & 0.8058 & 6.43 \\
\hline 0.2989 & 0.8234 & 0.7795 & 5.33 \\
\hline 0.3910 & 0.7899 & 0.7583 & 4.00 \\
\hline 0.5000 & 0.7568 & 0.7374 & 2.56 \\
\hline
\end{tabular}

Figs. 3 to 5 show the experimental and numerical results of impact force during impact process, where the solid line is the results based on $\mathrm{C} 1$, and the dotted line represented the results of C2. It is clearly that (1) the impact forces of numerical and experimental have similar change regulation, the higher initial impact velocity, the larger impact force, but lower impact time consumed. (2) The maximum values of impact forces based on $\mathrm{C} 1$ are larger than those of $\mathrm{C} 2$, which is due to the yield strength of C1 is larger than that of C2. (3) The numerical results of maximum impact force with different initial velocities are in reasonable agreement with those experimental results.
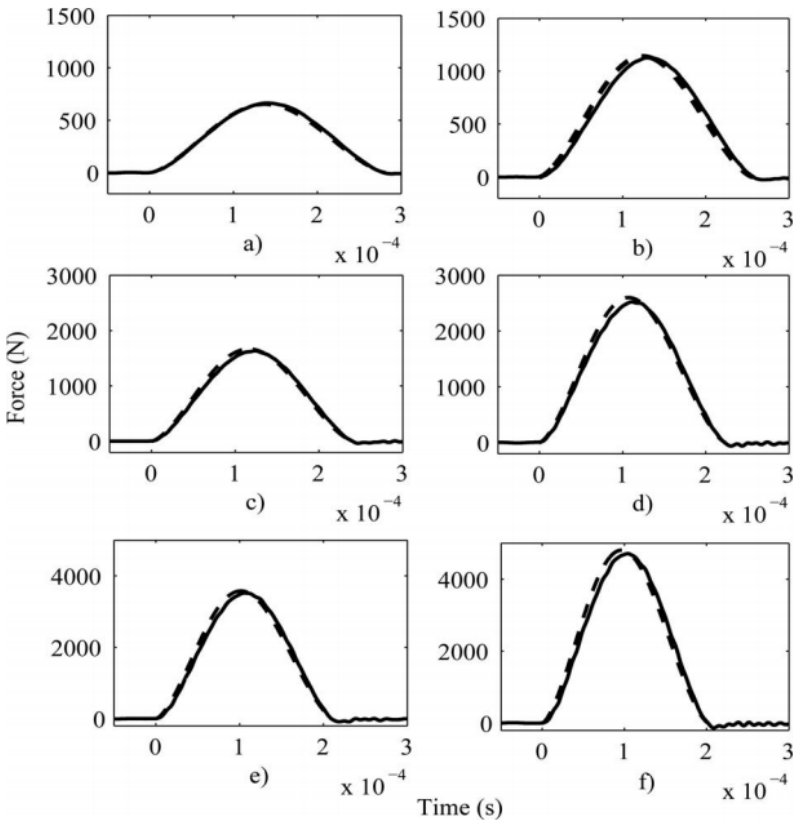

FIGURE III. EXPERIMENTAL RESULTS OF IMPACT FORCES WITH DIFFERENT INITIAL VELOCITY: (A) V=0.0938M/S; (B) $\mathrm{V}=0.15 \mathrm{M} / \mathrm{S}$; (C) $\mathrm{V}=0.206 \mathrm{M} / \mathrm{S}$; (D) $\mathrm{V}=0.2989 \mathrm{M} / \mathrm{S}$; (E) $\mathrm{V}=0.391 \mathrm{M} / \mathrm{S}$; (F) $\mathrm{V}=0.5 \mathrm{M} / \mathrm{S}$
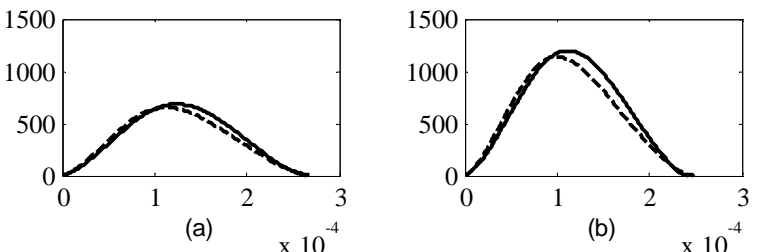

(b)

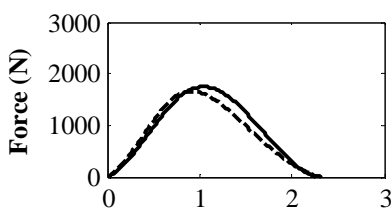

(c) $\times 10^{-4}$

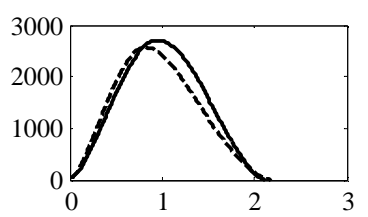

(d) $\quad \times 10^{-4}$
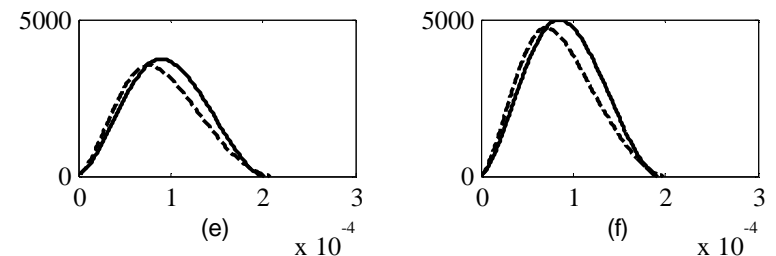

Time (s)

FIGURE IV. NUMERICAL RESULTS OF IMPACT FORCES WITH DIFFERENT INITIAL VELOCITY: (A) V=0.0938M/S; (B) $\mathrm{V}=0.15 \mathrm{M} / \mathrm{S}$; (C) $\mathrm{V}=0.206 \mathrm{M} / \mathrm{S}$; (D) $\mathrm{V}=0.2989 \mathrm{M} / \mathrm{S}$; (E) $\mathrm{V}=0.391 \mathrm{M} / \mathrm{S}$; (F) $\mathrm{V}=0.5 \mathrm{M} / \mathrm{S}$ 


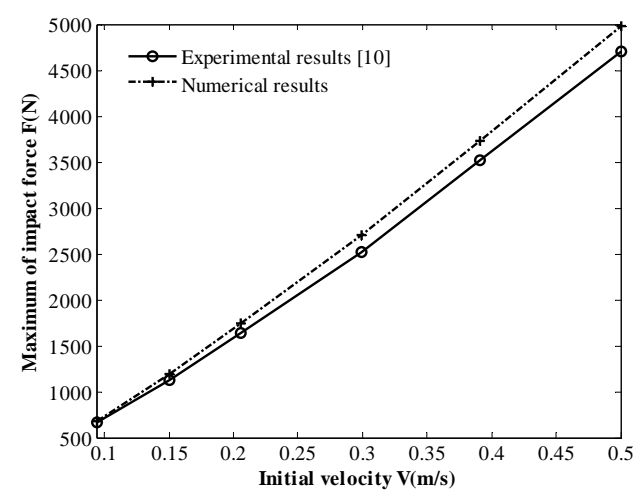

(a)

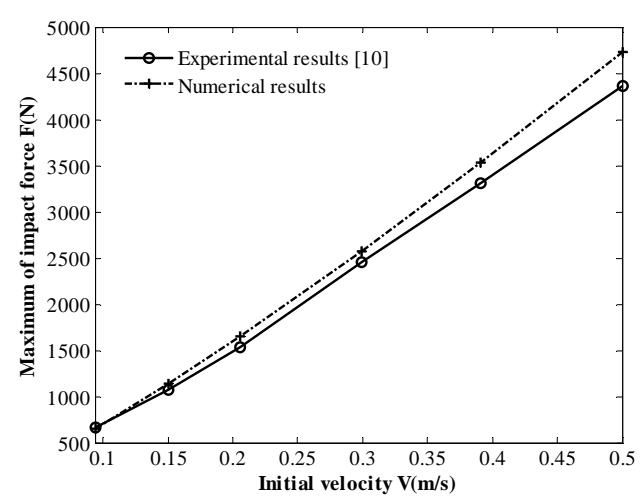

(b)

FIGURE V. MAXIMUM OF IMPACT FORCE: (A) SPECIMEN C1; (B) SPECIMEN C2

It is clear that the relative error between numerical and experimental results is no more than $10 \%$, which can be illustrated clearly in Table 5 and Table 6.

TABLE V. MAXIMUM IMPACT FORCE AND CORRESPONDING PERCENTAGE ERROR BASED ON EXPERIMENTAL AND NUMERICAL FOR SPECIMEN C1

\begin{tabular}{|c|c|c|c|}
\hline \multirow{2}{*}{$\begin{array}{c}\text { Initial impact } \\
\text { velocity [m/s] }\end{array}$} & \multicolumn{3}{|c|}{ Maximum impact force of Specimen C1 } \\
\cline { 2 - 4 } & Experimental & Numerical & Error [\%] \\
\hline 0.0938 & 663.0 & 683.46 & 3.09 \\
\hline 0.1500 & 1126.9 & 1194.57 & 6.00 \\
\hline 0.2060 & 1633.6 & 1741.46 & 6.60 \\
\hline 0.2989 & 2521.4 & 2709.09 & 7.44 \\
\hline 0.3910 & 3519.7 & 3725.38 & 5.84 \\
\hline 0.5000 & 4709.6 & 4985.94 & 5.87 \\
\hline
\end{tabular}

TABLE VI. MAXIMUM VALUES OF IMPACT FORCE AND CORRESPONDING PERCENTAGE ERROR BASED ON EXPERIMENTAL AND NUMERICAL FOR SPECIMEN C2

\begin{tabular}{|c|c|c|c|}
\hline \multirow{2}{*}{$\begin{array}{c}\text { Initial impact } \\
\text { velocity [m/s] }\end{array}$} & \multicolumn{3}{|c|}{ Maximum impact force of Specimen C2 } \\
\cline { 2 - 4 } & Experimental & Numerical & Error [\%] \\
\hline 0.0938 & 660.2 & 652.1 & 1.23 \\
\hline 0.1500 & 1076.6 & 1135.9 & 5.51 \\
\hline 0.2060 & 1533.1 & 1652.9 & 7.81 \\
\hline 0.2989 & 2447.9 & 2567.9 & 4.90 \\
\hline 0.3910 & 3303.3 & 3530.7 & 6.88 \\
\hline 0.5000 & 4364.6 & 4728.1 & 8.33 \\
\hline
\end{tabular}

\section{CONCLUSION}

The work presented an improved contact force model, which is obviously different from existing models, that is, the coefficient of restitution is related to initial impact velocity and the yield strength of material.

A typical pendulum experimental test rigs is applied to validate the improved contact force model, which is direct impact between a steel ball and a cylindrical specimen with different materials. And corresponding numerical results based on the improved model are also presented and compared. The results illustrated that the numerical results are in reasonable agreement with those experimental results, and the relative error for impact force and restitution coefficient are all no more than $10 \%$, which means the improved contact model can effectively describe the impact process, no matter what kind of initial impact velocity and material of impact body.

It is important to note that the results presented in the work do not consider the plastic deformation during impact process, which will be considered seriously in our future researches.

\section{ACKNOWLEDGMENT}

The work is supported by the Education Foundation of Shaanxi (Grant No. 17JK0551), and Doctor Starting Foundation of Xi'an University of Technology (Grant No. 106-451117002). The authors would like to express their appreciation to the agencies.

\section{REFERENCES}

[1] P. Flores, J. Ambrósio, Revolute joints with clearance in multibody systems, Computers and Structures [J], 82(2004)1359-1369.

[2] M. Machado, P. Moreira, P. Flores, H. M. Lankarani, Compliant contact force models in multibody dynamics: Evolution of the Hertz contact theory [J], Mechanism and Machine Theory, 53(2012)99-121.

[3] S. Erkaya, I. Uzmay, Experimental investigation of joint clearance effects on the dynamics of a slider-crank mechanism [J], Multibody System Dynamics, 24(2010)81-102.

[4] S. Yaqubi, M. Dardel, H.M. Daniali, M.H. Ghasemi, Modeling and control of crank-slider mechanism with multiple clearance joints. Multibody System Dynamics, 36(2) (2016)143-167.

[5] P. Flores, A parametric study on the dynamic response of planar multibody systems with multiple clearance joints [J], Nonlinear Dynamics, 61(2010)633-653.

[6] Hertz H. Über dies Berührung fester elasticher Körper [J]. Journal reine und angewandte Mathematik, 1881, (92): 156-171.

[7] Liu C S, Zhang K, Yang R. The compliance contact model of cylindrical joints with clearance [J]. Acta Mechanica Sinica, 2005, 21(5): 451-458.

[8] K. H. Hunt, F.R.E. Crossley, Coefficient of restitution interpreted as damping in vibroimpact [J]. Journal of Applied Mechanics, 7(1975)440-445.

[9] H.M. Lankarani, P.E. Nikravesh, A contact force model with hysteresis damping for impact analysis of multi-body systems [J], Journal of Mechanical Design, 112(1990)368-376.

[10] Y. Gonthier, J. McPhee, C. Lange, J. C. Piedboeuf, A regularized contact model with asymmetric damping and dwell-time dependent friction [J], Multibody System Dynamics, 11(2004)209-233.

[11] Q. Zhiying, L. Qishao, Analysis of impact process based on restitution coefficient [J], Journal of Dynamics and Control, 4(2006)294-298.

[12] Flores P, Machado M, Silva M T, Martins J.M. On the continuous contact force models for soft materials in multibody dynamics [J]. Multibody system dynamics, 2011, 25: 357-375. 
[13] Z.F. Bai, Y. Zhao. A hybrid contact force model of revolute joint with clearance for planar mechanical systems [J]. International Journal of Nonlinear Mechanics, 48(2013)15-36.

[14] X.P. Wang, G. Liu, S.J. Ma. Dynamic analysis of planar mechanical systems with clearance joints using a new nonlinear contact force model, Journal of Mechanical Science and Technology, 30 (4) (2016)1537 1545.

[15] C.W. Stammers, M Ghazavi. A theoretical and experimental study of the dynamics of a four-bar China with bearing clearance: pin motion, contact loss and impact [J]. Journal of Sound and Vibration, 1991, 15 (2)301-315.

[16] Y.N. Zhang, S. Inna. Validation of nonlinear viscoelastic contact force models for low speed impact [J]. Journal of Applied Mechanics, 2009, 76 (5)911-914. 